\title{
Unusual surface schooling behavior by bullethead parrotfish (Chlorurus sordidus)
}

Received: 6 June 2010/ Accepted: 21 June 2010/Published online: 9 July 2010

(C) Springer-Verlag 2010
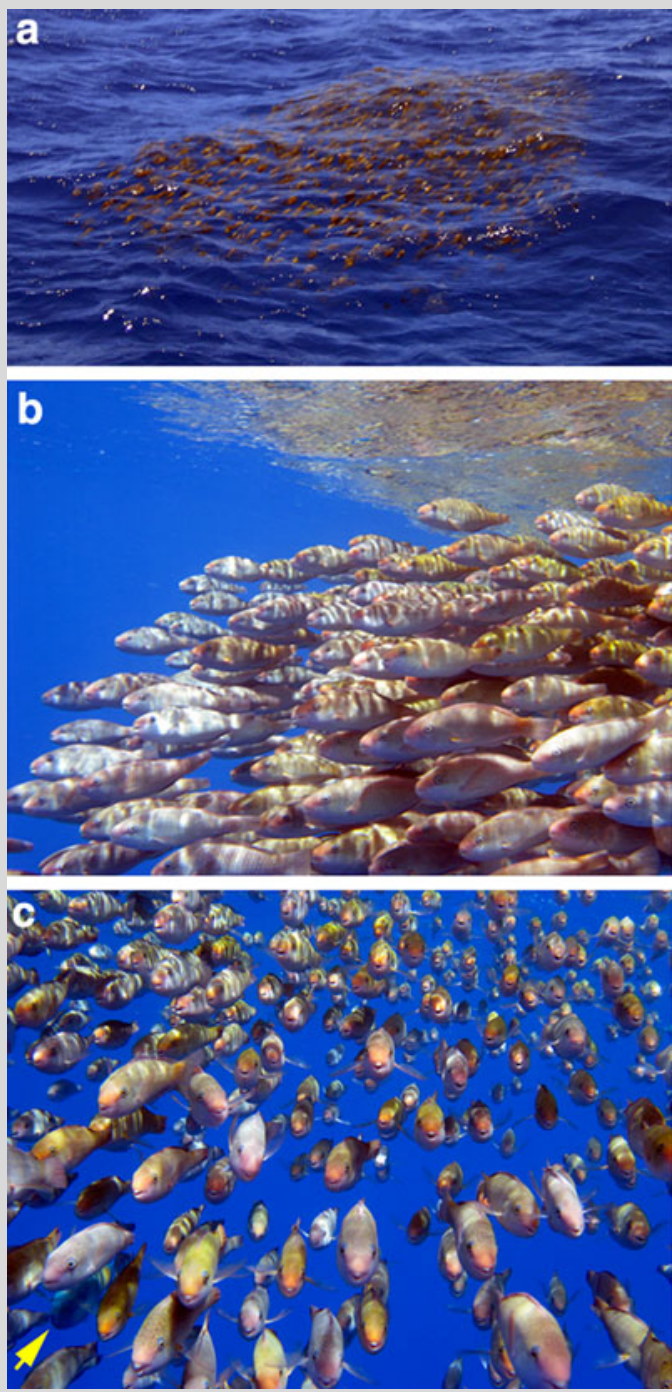

Fig. 1 Bullethead parrotfish school swimming at surface. a Surface view, b Oblique underwater view of leading edge of school showing pale coloration of initial-phase individuals, $\mathbf{c}$ Front underwater view of school showing terminal-phase individual (yellow arrow bottom left) surrounded by initial-phase conspecifics
Parrotfishes routinely form large schools close to the substrate while foraging, migrating or spawning (Johannes 1981). On 30th May 2010 at French Frigate Shoals atoll (N 23.63601, W 166.17235), northwestern Hawaiian Islands, we observed a school of bullethead parrotfish (Chlorurus sordidus) swimming at the surface in a depth of $40 \mathrm{~m}$ (Fig. 1a, b). The parrotfish were initially sighted at $1355 \mathrm{~h}$ and swam at the surface until $1410 \mathrm{~h}$ when the entire school descended to the reef at a depth of $20 \mathrm{~m}$. The school was 3-4 m in diameter and consisted of approximately 800 individuals ranging in size from 15 to $25 \mathrm{~cm}$ total length. Most fish displayed pale, initial-phase coloration, but two terminal-phase individuals were also sighted swimming in the school (Fig. 1c). The school was easily approached by an 8-m boat and made no attempt to flee or alter course. Predators were abundant in the area of observation, with numerous large (87-121 cm Fork Length) giant trevally (Caranx ignobilis) seen within $200 \mathrm{~m}$ of the parrotfish, but none observed attacking the school. The only predators observed foraging on the school were six Great Frigate birds (Fregata minor palmerstoni), of which one was seen capturing a fish.

The parrotfish behavior bore clear hallmarks of a spawning migration. The school was sighted 4 days after the full moon (27 May 2010 at 2307 h), and many reef fishes including other parrotfishes (Gladstone 1996) are known to aggregate for spawning around the full moon. The school was easily approachable, which is another characteristic of otherwise wary reef fishes immediately before and during spawning (Johannes 1981). Swimming at the surface in a predator-rich environment seems risky but our direct observations show predation can be minimal during such events. To our knowledge, this is the first time this phenomenon has been documented in parrotfishes.

\section{References}

Gladstone W (1996) Unique annual aggregation of longnose parrotfish (Hipposcarus harid) at Farasan Island (Saudi Arabia, Red Sea). Copeia 1996:483-485

Johannes RE (1981) Words of the lagoon. Univ. of California Press, Berkeley, CA

Electronic supplementary material The online version of this article (doi:10.1007/s00338-010-0657-7) contains supplementary material, which is available to authorized users.

\section{G. Meyer $(\bowtie)$ · C. E. Clark}

Hawaii Institute of Marine Biology, University of Hawaii at Manoa, P.O. Box 1346, Coconut Island, Kaneohe, HI 96744, USA

e-mail: carlm@hawaii.edu

\section{J. J. Dale}

Department of Zoology, Edmonson Hall, University of Hawaii at Manoa, Honolulu, HI 96822, USA 